\title{
Is Outpatient Control of Long-Term Non-Invasive Ventilation Feasible in Chronic Obstructive Pulmonary Disease Patients?
}

\author{
Sarah Bettina Schwarz Jens Callegari Christine Hamm Wolfram Windisch \\ Friederike Sophie Magnet \\ Department of Pneumology, Cologne Merheim Hospital, Kliniken der Stadt Köln gGmbH, Witten/Herdecke \\ University, Faculty of Health/School of Medicine, Cologne, Germany
}

\section{Keywords \\ Home mechanical ventilation - Health-related quality of life - Outpatient setting · Chronic obstructive pulmonary disease $\cdot$ Respiratory failure}

\begin{abstract}
Background: Long-term non-invasive ventilation (NIV) is an established and increasingly used treatment option for patients with chronic hypercapnic chronic obstructive pulmonary disease (COPD). Following inpatient NIV establishment, inpatient control visits regularly occur thereafter. However, it remains unclear whether such control visits can also be performed in an outpatient setting, which, in turn, would reduce costs, patient burden and the complications related to hospitalization. Objectives: To investigate an outpatient setting with predefined criteria for hospitalization for patients with chronic hypercapnic COPD. Methods: An outpatient clinic located within the hospital in the vicinity of the respiratory care unit provided predefined criteria for hospitalization of COPD patients receiving long-term NIV therapy. The results of this setting were retrospectively analysed. Results: A total of 130 outpatient visits ( 80 patients) were analysed. In 93 cases (71.5\%), hospital admission was not necessary,
\end{abstract}

๑ 2017 S. Karger AG, Basel while hospitalization was performed in 37 cases (28.5\%). Out of these, 7 cases with acute conditions required prompt hospitalization. Patients without hospitalization had better $\mathrm{PaCO}_{2}$ values ( $45.40 \pm 5.27$ vs. $\left.50.05 \pm 8.04, p=0.002\right)$ and Severe Respiratory Insufficiency Questionnaire Summary scores (55.54 \pm 19.74 vs. $41.82 \pm 19.59, p=0.012)$. Conclusion: Outpatient control of long-term NIV in a hospital setting is feasible and has the capacity to identify stable COPD patients in whom NIV therapy is sufficient according to predefined criteria. These patients may not require hospitalization and may account for more than two thirds of cases.

(c) 2017 S. Karger AG, Basel

\section{Introduction}

Nocturnal long-term non-invasive ventilation (NIV) is a well-established, increasingly used modern therapeutic option for patients with chronic hypercapnic respiratory failure that arises from end-stage chronic obstructive pulmonary disease (COPD) [1,2]. While early random-

S.B. Schwarz and J. Callegari contributed equally to this work.

\section{KARGER}

E-Mail karger@karger.com

www.karger.com/res
Prof. Dr. Wolfram Windisch

Cologne Merheim Hospital, Kliniken der Stadt Köln gGmbH Witten/Herdecke University, Faculty of Health/School of Medicine Ostmerheimer Strasse 200, DE-51109 Köln (Germany)

E-Mail windischw@kliniken-koeln.de 
ized controlled trials (RCTs) concluded that there was insufficient evidence to support recommendation of routine NIV use in COPD patients [3-7], two recent RCTs have clearly shown that when NIV is administered with the aim of improving elevated $\mathrm{PaCO}_{2}$ values, it has the capacity to improve outcome and health-related quality of life (HRQL) [8,9]. Higher than usual ventilator settings are necessary to augment alveolar ventilation and, in turn, improve blood gases. This approach has been defined as high-intensity NIV [10-13].

Based on these findings, and given the increasing incidence and prevalence of COPD, the number of COPD patients receiving long-term NIV is steadily rising [1416]. These patients require regular follow-up visits, which are inevitably needed to control for NIV efficiency, adherence to treatment, and problems - technical or otherwise - that are associated with NIV $[16,17]$. In Germany, this is usually performed on a regular basis in the inpatient hospital setting, allowing for nocturnal measurements of gas exchange and sleep quality while NIV is running $[16,18]$. In addition, the recommendation for hospitalizing these patients is based not only on the severity of the disease, but also on the fact that modifications to the ventilator settings have a strong physiological influence and hence need to be evaluated for their potential impact on nocturnal ventilation efficiency.

In contrast, regular hospitalization is a burden for these patients and has been linked to an increased risk of nosocomial infections in ICU patients [19]. In addition, there is increasing evidence for successful outpatient management in non-COPD patients requiring long-term NIV [20-24]. However, most of these patients receive long-term NIV due to neuromuscular and chest wall diseases and therefore the results are not comparable to COPD patients.

Furthermore, the increasing number of COPD patients treated with long-term NIV is likely to be associated with higher costs, while the need for regular hospitalization can significantly limit bed availability for other patients. In addition, some patients are stable and do not require any change in NIV during hospitalization, questioning the necessity for regular inpatient treatment.

As a consequence, the time has come to evaluate the impact of outpatient care in COPD patients undergoing long-term NIV therapy. Other European countries already provide outpatient NIV clinics for example Great Britain or the Netherlands. Especially in the Netherlands, it is standard that NIV patients are visited at home and also receive nocturnal transcutaneous carbon dioxide measurements in the home environment [25]. The aim of the current trial was therefore to evaluate the results of an outpatient clinic pilot project for long-term NIV-treated COPD patients. Such findings are expected to be valuable for designing future RCTs on the role of outpatient management in COPD patients receiving long-term NIV therapy.

\section{Methods}

\section{Subjects and Study Design}

This was an investigator-initiated single-centre retrospective trial. Data were collected from all COPD patients treated between January 2016 and January 2017 in the outpatient NIV unit of the Department of Pneumology, Cologne Merheim Hospital, Witten/ Herdecke University, Faculty of Health/School of Medicine. Prior to the analysis, the ethics committee of the University of Witten/ Herdecke were contacted regarding the need for ethical approval, which was not required in this retrospective trial. All patients suffered from COPD GOLD stage IV according to the GOLD guidelines [7] and had previously been hospitalized for the establishment of long-term NIV prior to the analysis. Documented information on ventilator settings, blood gas values, demographic data, and HRQL measurements was selected for analysis.

For hospital admission, two categories were defined according to hospitalization priority: prompt admission (same day) versus short-term hospitalization (defined as hospital admission within $<2$ months).

\section{Measurements and Ventilator Settings}

NIV was applied using either assisted pressure-controlled ventilation, pressure-supported ventilation or pressure-controlled ventilation. NIV was delivered via nasal or full-face masks. Daytime blood gases were measured at rest and obtained from the arterialized earlobe as previously described (ABL 800 flex, Radiometer, Denmark) [26]. The Severe Respiratory Insufficiency Questionnaire (SRI) was designed and validated for HRQL in patients receiving long-term NIV therapy $[27,28]$. Transcutaneous $\mathrm{PCO}_{2}$ $\left(\mathrm{PtcCO}_{2}\right)\left(\right.$ SenTec Digital Monitoring System; VStats-Software ${ }^{\circledR}$ : 4.00; SenTec AG, Therwil, Switzerland) measurements were performed during daytime ventilation in selected patients $[29,30]$.

Therapy adherence was evaluated from readings generated by the built-in ventilator software. Read-outs from each of the ventilators were performed by individual ventilator software (ResScan: 5.5, ResMed Limited, San Diego, CA, USA; VENTIviews: 1.0, Weinmann GmbH + Co. KG, Hamburg, Germany; Vivo PC Software: 4.01, Breas medical AB, Mölnlycke, Sweden; Vivo 50 PC Software: 3.1, Breas medical AB; DirectView: 1.3, Philips Respironics, Koninklijke, the Netherlands; EncoreBasic: 2.8, Philips Respironics).

\section{Outpatient Setting}

As a pilot project, the Cologne Merheim Hospital offers longterm NIV patients an outpatient care service that is located next to the Respiratory Care Unit. Hereby, two beds equipped with modalities for full polysomnography, $\mathrm{PtcCO}_{2}$ measurements as well as the option for invasive and non-invasive cardiovascular and respiratory monitoring were provided for outpatient NIV manage- 
Fig. 1. Outpatient clinic setting. SRI, Severe Respiratory Insufficiency Questionnaire; $\mathrm{NIV}$, non-invasive ventilation; $\mathrm{PtcCO}_{2}$, partial pressure of transcutaneous carbon dioxide.
Basic measurements

- Questionnaires:

- Severe Respiratory Insufficiency

Questionnaire (SRI)

- NIV-related questions

- Capillary blood gas analysis

- Read-out of the internal storage

- Anamnesis

- Focused clinical examination

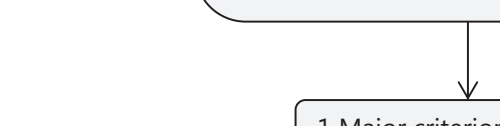

1 Major criterion reached?

- $\mathrm{PaCO}_{2} \geq 55 \mathrm{~mm} \mathrm{Hg}$

- $\mathrm{pH}<7.35$

- Acute exacerbation

No
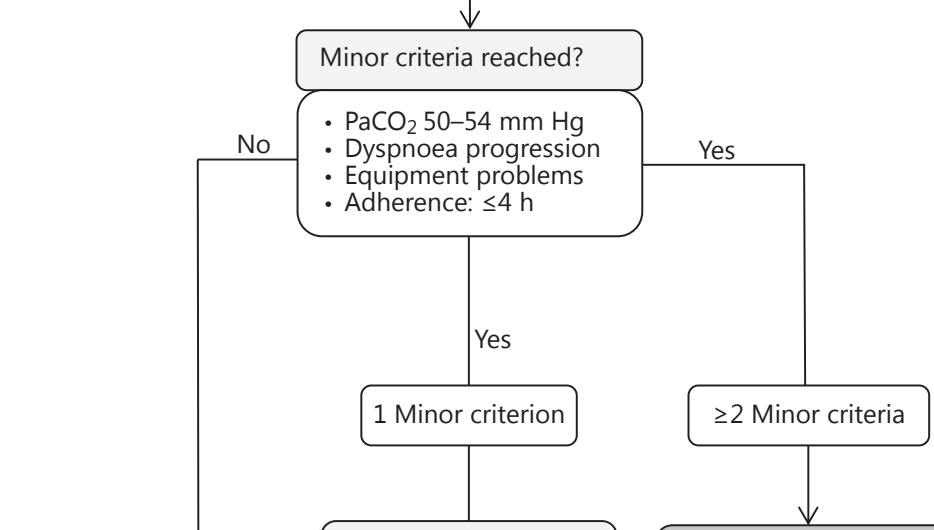

Daytime ventilation with $\mathrm{PtcCO}_{2}$ monitoring

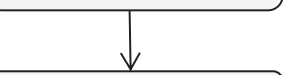

Short-term inpatient admission

No

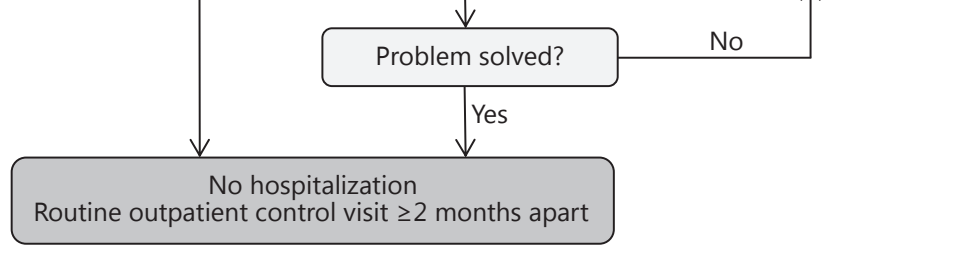

ment. A flowchart describing the outpatient NIV set-up is illustrated in Figure 1.

Prompt hospitalization was recommended if at least one of the following major criteria was identified: severe hypercapnia $\left(\mathrm{PaCO}_{2}\right.$ $\geq 55 \mathrm{~mm} \mathrm{Hg}$ ), respiratory acidosis $(\mathrm{pH} \leq 7.35)$ or acute exacerbation of COPD defined as an acute worsening of respiratory symptoms which results in additional therapy [7]. In addition, minor criteria were defined as follows: $\mathrm{PaCO}_{2} 50-54 \mathrm{~mm} \mathrm{Hg}$, low adherence to therapy defined by $\leq 4 \mathrm{~h}$ /day of ventilator use, problems with equipment, or clinical issues such as progression of dyspnoea. In the case of two minor criteria being identified, short-term hospital admission was recommended, even though daytime ventilation with $\mathrm{PtcCO}_{2}$ monitoring was performed in parallel to reduce problems and determine the level of urgency for hospitalization.
In the case of one minor criterion being identified, daytime ventilation (min. $1 \mathrm{~h}$, max. $4 \mathrm{~h}$ ) with $\mathrm{PtcCO}_{2}$ monitoring was carried out with the aim of addressing the problem at hand. Short-term hospital admission was recommended if this strategy was unsuccessful. In the remaining cases where neither major nor minor criteria were met, or problems were resolved, patients were not hospitalized and instead planned for routine outpatient control every $\geq 2$ months.

\section{Data Collection and Statistical Analysis}

The following data were collected: sex, birth date, date and circumstances of NIV initiation (initiation because of chronic hypercapnia, after acute hypercapnic exacerbation or after weaning), smoking status and index, time remaining until next control visit, 


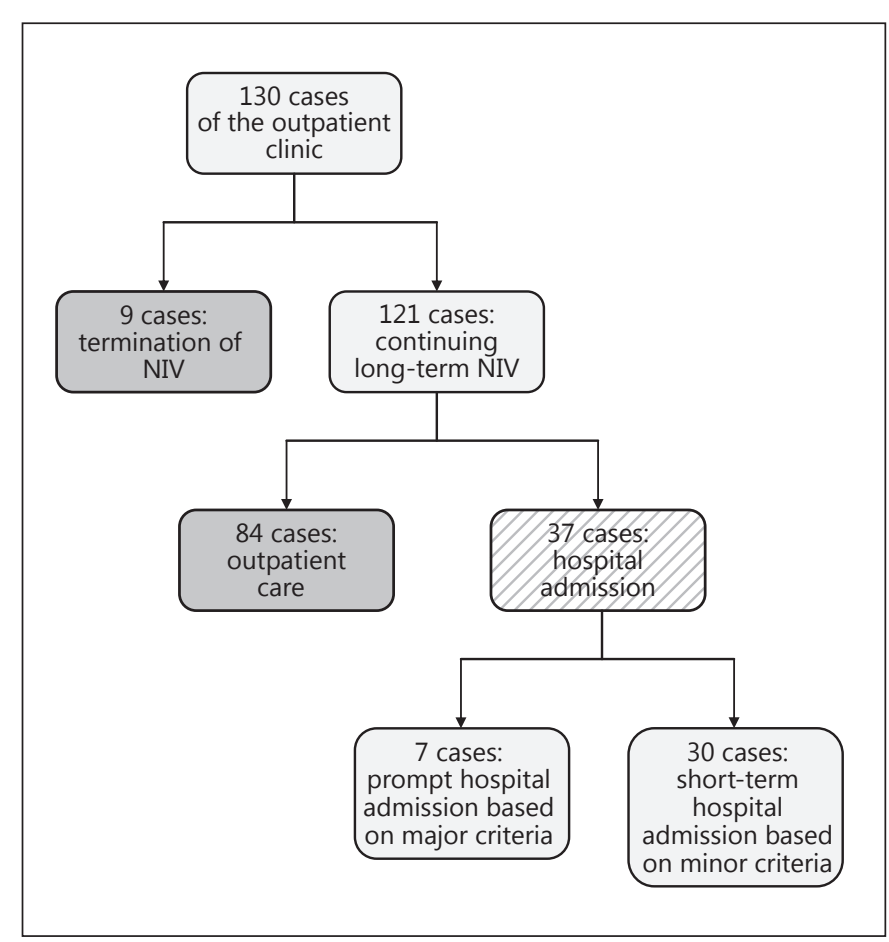

Fig. 2. Flowchart showing the distribution of study cases. NIV, non-invasive ventilation.

long-term oxygen therapy, ventilator settings, duration of NIV application per day and further treatment recommendations.

Statistical analysis was performed using Sigma-Plot ${ }^{\circledR}$ (Version 12.3, Systat Software, Inc., Point Richmond, CA, USA). Means and standard deviations are reported for demographics, ABG results and ventilator settings. Unpaired $t$ tests for continuous variables were used to compare patient characteristics between the two groups (inpatient versus outpatient), and the Mann-Whitney rank sum test was used for non-normally distributed data.

\section{Results}

A total of 130 outpatient visits by 80 patients were analysed. Demographics, ventilator settings and diagnostic data are given in Table 1. A flowchart summarizing the design of the study cases is illustrated in Figure 2.

In 84 cases $(64.6 \%)$, NIV was continued without hospital admission. In contrast, hospitalization was carried out in 37 cases (28.5\%), with the aim of optimizing treatment and solving problems associated with NIV. Amongst these hospitalized patients, prompt hospitalization was required in $18.9 \%(n=7)$ and short-term hospital admission was recommended for the remaining $81.1 \%(n=30)$, even though 12 out of these patients were admitted later

Is Outpatient Control of Long-Term NIV Feasible in COPD Patients?
Table 1. Patient characteristics and ventilator settings $(n=80)$
Males, $n(\%)$

Age, years

Body mass index

Smoking status (active:prior)

Smoking index, pack years

Time under NIV, years

LTOT (L/min during rest; $n=80$ )

NIV initiation, $n(\%)$

Following acute NIV

Chronic elective NIV

NIV following prolonged weaning

Unknown

Ventilator settings

IPAP, $\mathrm{cmH}_{2} \mathrm{O}$

EPAP, $\mathrm{cmH}_{2} \mathrm{O}$

$\mathrm{BF}$ per min

Adherence, hours per day
Supplemental oxygen (yes:no)
$32(40)$

$67.11 \pm 8.44$

$22: 58$

$54.23 \pm 23.45$

$75: 5$

$1.54 \pm 1.19$

$36(45)$

$30(37.5)$

$9(11.25)$

$5(6.25)$

$23.90 \pm 4.39$

$5.65 \pm 1.20$

$16.55 \pm 2.22$

$6.58 \pm 3.65$
$26.97 \pm 7.27$

$2.28 \pm 2.52$

LTOT, long-term oxygen therapy; IPAP, inspiratory positive airway pressure; EPAP, expiratory positive airway pressure; BF, breathing frequency.

Table 2. Daytime blood gases and oxygen flow rates in patients who required hospitalization (inpatient care) versus those who did not (outpatient care)

\begin{tabular}{lccc}
\hline & $\begin{array}{l}\text { Outpatient care } \\
(n=84)\end{array}$ & $\begin{array}{l}\text { Inpatient care } \\
(n=37)\end{array}$ & $p$ value \\
\hline $\mathrm{PaCO}_{2}, \mathrm{~mm} \mathrm{Hg}$ & $45.40 \pm 5.27$ & $50.05 \pm 8.04$ & 0.002 \\
$\mathrm{PaO}_{2}, \mathrm{~mm} \mathrm{Hg}$ & $65.97 \pm 10.98$ & $61.79 \pm 12.08$ & 0.034 \\
$\mathrm{pH}_{\mathrm{HCO}}^{3-}, \mathrm{mmol} / \mathrm{L}$ & $7.40 \pm 0.03$ & $7.39 \pm 0.03$ & 0.050 \\
$\mathrm{LTOT}, \mathrm{L} / \mathrm{min}$ & $26.99 \pm 2.44$ & $27.98 \pm 3.17$ & 0.040 \\
& $1.47 \pm 1.52$ & $1.73 \pm 1.54$ & 0.239 \\
\hline
\end{tabular}

$\mathrm{PaCO}_{2}$, arterial partial pressure of carbon dioxide; $\mathrm{PaO}_{2}$, arterial partial pressure of oxygen; $\mathrm{HCO}_{3}{ }^{-}$, bicarbonate; LTOT, longterm oxygen therapy.

than 2 months following outpatient control. In 9 cases (6.9\%), no follow-up was necessary because NIV was terminated prior to control visits, due to successful withdrawal trial with no further indication for this therapy. Five out of the 9 cases (55.6\%) were initiated following acute exacerbation. Termination of NIV was based on now obsolete indication criteria. These patients were therefore excluded from the final analysis.

Most recommendations for hospital admission were based on the results of the blood gas analysis. Consequently, blood gas values differed significantly between 
Table 3. Severe Respiratory Insufficiency Questionnaire scores in patients who required hospitalization (inpatient care) versus those who did not (outpatient care)

\begin{tabular}{lllc}
\hline & $\begin{array}{l}\text { Outpatient care } \\
(n=84)\end{array}$ & $\begin{array}{l}\text { Inpatient care } \\
(n=37)\end{array}$ & $p$ value \\
\hline Respiratory complaints & $34.72 \pm 20.20$ & $32.25 \pm 25.04$ & 0.678 \\
Physical functioning & $63.61 \pm 16.71$ & $50.29 \pm 17.49$ & 0.005 \\
Attendant symptoms and sleep & $65.24 \pm 20.63$ & $64.11 \pm 19.52$ & 0.835 \\
Social relationships & $55.69 \pm 25.22$ & $44.89 \pm 25.21$ & 0.114 \\
Anxiety & $53.55 \pm 19.94$ & $46.30 \pm 16.35$ & 0.151 \\
Psychological well-being & $49.79 \pm 21.84$ & $40.61 \pm 20.31$ & 0.111 \\
Social functioning & $54.02 \pm 15.83$ & $45.75 \pm 14.59$ & 0.048 \\
Summary scale & $55.54 \pm 19.74$ & $41.82 \pm 19.59$ & 0.012 \\
\hline
\end{tabular}

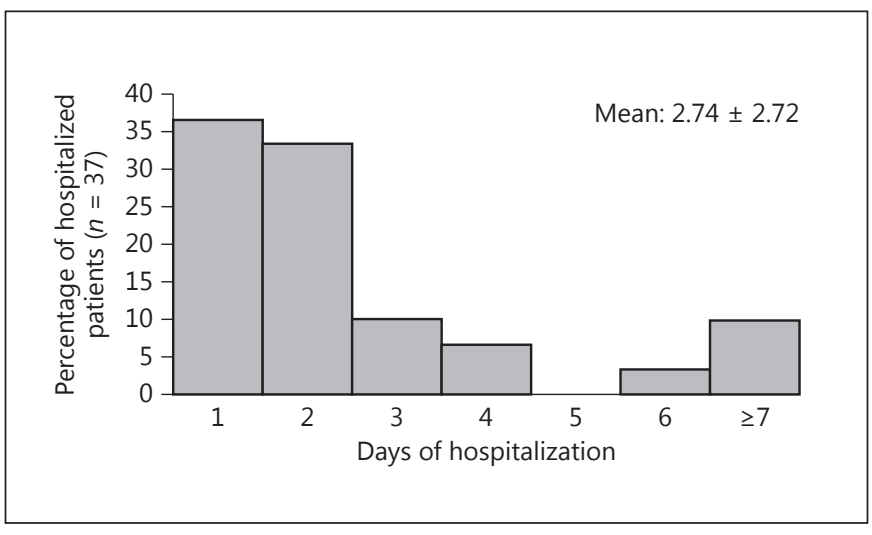

Fig. 3. Length of hospital stay.

patients who required hospitalization and those who did not, as specified in Table 2 .

Daytime ventilation with $\mathrm{PtcCO}_{2}$ monitoring was performed in $10 \%(n=13)$ of outpatient visits; 8 of these did not need recommendations for hospitalization, since problems with NIV related to the predefined criteria could be managed successfully.

Clear differences in SRI scores were observed between patients who required hospitalization versus patients who did not (Table 3). The length of inpatient stay is illustrated in Figure 3, showing that only short hospital stays of 2 days or less were necessary in 22 cases (70\%) of hospitalized patients. In contrast, 4 cases ( $13 \%$ of the hospitalized patients) were hospitalized for 6 days or longer. Reasons for this prolonged hospital stay were as follows: acute exacerbation $(n=2)$, severe hypercapnia $\left(\mathrm{PaCO}_{2} 60\right.$ $\mathrm{mm} \mathrm{Hg}, n=1)$, and symptoms of angina pectoris with known coronary heart disease $(n=1)$.

\section{Discussion}

This is the first study to carry out an analysis of a specialized outpatient care system for COPD patients already receiving long-term NIV therapy at home. The main findings of this trial are as follows:

Firstly, $72 \%(n=93)$ of all the cases evaluated in a clearly defined outpatient setting were not hospitalized. Out of these patients continuing home NIV, 84 were deemed not to require inpatient care, according to predefined criteria based on blood gas analysis, subjective parameters such as exacerbation, dyspnoea or problems related to NIV, and adherences to NIV. In contrast, 9 patients no longer required long-term NIV.

Secondly, only less than one third of patients who were scheduled for regular outpatient control visits eventually required in-hospital treatment. Here, the major proportion of these patients requiring hospitalization were scheduled for short-term admission within 2 months following outpatient control, while only a small number of patients required prompt hospitalization on the same day that they visited the outpatient clinic.

Thirdly, as a consequence of the algorithm that determined the need for hospitalization, patients who did not require hospital admission not only had better blood gas analysis results, but also better SRI-assessed HRQL.

There were some limitations to the present analysis. Firstly, the study was retrospectively performed and hence needs further validation by prospective RCTs; however, the advantage of this study is that the findings may help to design future prospective trials. Secondly, the study did not include data for lung function, as current lung function measurements were not available in some patients. Thirdly, there was no analysis of follow-up visits. 
Therefore, the outcome of outpatient management of long-term NIV remains to be elucidated.

Despite these limitations, the present study has some important clinical implications for the management of long-term NIV in COPD patients. Most importantly, our findings suggest that a significant number of patients with COPD can indeed be managed in an outpatient setting, without inpatient control visits. These patients have acceptable blood gases and SRI scores that are comparable to those from patients who in previous studies were re-evaluated following a hospital admission [31]. This is an important observation given that outpatient management of these patients can indeed reduce costs as well as hospitalization-related complications such as nosocomial infections, even though this has not yet been investigated and therefore remains speculative.

Most hospitalized patients can be managed during a short in-hospital period of 2 days or less. The frequent reason for hospitalization in the present study cohort was to manage significant hypercapnia and clinical problems. Another important issue, however, refers to the observation that some patients required prompt hospitalization and a few patients also required longer stays in hospital. Therefore, any future outpatient clinics designed for monitoring long-term NIV should also allow the possibility of admitting the patient to hospital immediately. The most optimal outpatient setting for this would be within the NIV unit of a hospital specialized for NIV.

On the other hand, the present study shows that while nearly half of the patients received long-term NIV following acute NIV in hospital, NIV could be terminated there- after in at least some of these patients. Therefore, both oversupply and undersupply need to be avoided, and any setting, whether it be in- or outpatient, should be capable of addressing this important issue. Thereby, it remains questionable whether NIV should be automatically continued once patients are established on long-term NIV after repeated inpatient control visits.

In conclusion, outpatient control of long-term NIV is feasible and has the capacity to identify stable COPD patients whose NIV therapy suffices to the extent of precluding the need for hospitalization. In addition, outpatient settings for long-term NIV monitoring should also have the means to provide prompt hospitalization for unstable patients or those with insufficient NIV treatment. Further prospective trials are needed to clearly define the criteria for in- and outpatient care of COPD patients receiving long-term NIV therapy.

\section{Acknowledgements}

We acknowledge Dr. Sandra Dieni, $\mathrm{PhD}$, for helpful comments on the manuscript before submission.

\section{Financial Disclosure and Conflicts of Interest}

The authors S.B.S., J.C., C.H., W.W., and F.S.M. have accepted speaking fees and/or travel funding from companies involved in mechanical ventilation.

The authors state that neither the study design, results, interpretation of the findings, nor any other subject discussed in the submitted manuscript was dependent on financial support.

\section{References}

1 Windisch W, Storre JH, Köhnlein T: Nocturnal non-invasive positive pressure ventilation for COPD. Expert Rev Respir Med 2015;9: 295-308.

2 Crimi C, Noto A, Princi P, et al: Domiciliary non-invasive ventilation in COPD: an international survey of indications and practices. COPD 2016;13:483-490.

3 Casanova C, Celli BR, Tost L, et al: Long-term controlled trial of nocturnal nasal positive pressure ventilation in patients with severe COPD. Chest 2000;118:1582-1590.

4 Clini E, Sturani C, Rossi A, et al: The Italian multicentre study on noninvasive ventilation in chronic obstructive pulmonary disease patients. Eur Respir J 2002;20:529-538.

5 McEvoy RD, Pierce RJ, Hillman D, et al: Nocturnal non-invasive nasal ventilation in stable hypercapnic COPD: a randomised controlled trial. Thorax 2009;64:561-566.
6 Struik FM, Lacasse Y, Goldstein R, et al: Nocturnal noninvasive positive pressure ventilation in stable COPD. A systematic review and individual patient data metaanalysis. Respir Med 2014;108:329-337.

7 From the Global Strategy for the Diagnosis, Management and Prevention of COPD, Global Initiative for Chronic Obstructive Lung Disease (GOLD). 2017. http://goldcopd. org (accessed July 30, 2017).

8 Köhnlein T, Windisch W, Köhler D, et al: Non-invasive positive pressure ventilation for the treatment of severe stable chronic obstructive pulmonary disease. A prospective, multicentre, randomised, controlled clinical trial. Lancet Respir Med 2014;2:698-705.
9 Murphy PB, Rehal S, Arbane G, et al: Effect of home noninvasive ventilation with oxygen therapy vs oxygen therapy alone on hospital readmission or death after an acute COPD exacerbation: a randomized clinical trial. JAMA 2017;317:2177-2186.

10 Windisch W, Kostic S, Dreher M, et al: Positive pressure ventilation aimed at a maximal reduction of $\mathrm{PaCO}_{2}$. Chest 2005;128:657662 .

11 Windisch W, Haenel M, Storre JH, Dreher M: High-intensity non-invasive positive pressure ventilation for stable hypercapnic COPD. Int J Med Sci 2009;6:72-76.

12 Dreher M, Storre JH, Schmoor C, Windisch W: High-intensity versus low-intensity noninvasive ventilation in patients with stable hypercapnic COPD: a randomised crossover trial. Thorax 2010;65:303-308. 
13 Schwarz SB, Magnet FS, Windisch W: Why high-intensity NPPV is favourable to low-intensity NPPV: clinical and physiological reasons. COPD 2017;14:389-395.

14 Statistisches Bundesamt: DRG Statistics 2010-2014. 2016. https://www.destatis.de/ DE/ZahlenFakten/GesellschaftStaat/Gesundheit/Krankenhaeuser/Methoden/FallpauschalenbezogeneKrankenhausstatistik. html (accessed June 1, 2017).

15 Janssens JP, Derivaz S, Breitenstein E, et al: Changing patterns in long-term noninvasive ventilation: a 7 -year prospective study in the Geneva Lake area. Chest 2003;123:67-79.

16 Windisch W, et al: Guidelines for non-invasive and invasive mechanical ventilation for treatment of chronic respiratory failure. Revision 2017. http://www.awmf.org/uploads/tx szleitlinien/020_0081_S2k_NIV_Nichtinvasive_invasive_Beatumung_Insuffizienz 2017-07.pdf (accessed July 25, 2017).

17 Borel JC, Pelletier J, Taleux N, et al: Parameters recorded by software of non-invasive ventilators predict COPD exacerbation: a proof-of-concept study. Thorax 2015;70:284285.

18 Leger P, Laier-Groeneveld G: Infrastructure, funding and follow-up in a programme of noninvasive ventilation. Eur Respir J 2002;20: 1573-1578.
19 Kohlenberg A, Schwab F, Behnke M, et al: Pneumonia associated with invasive and noninvasive ventilation: an analysis of the German nosocomial infection surveillance system database. Intensive Care Med 2010;36: 971-978.

20 Sheers N, Berlowitz DJ, Rautela L, et al: Improved survival with an ambulatory model of non-invasive ventilation implementation in motor neuron disease. Amyotroph Lateral Scler Frontotemporal Degener 2014;15:180184.

21 Hazenberg A, Kerstjens HAM, et al: Initiation of home mechanical ventilation at home: a randomised controlled trial of efficacy, feasibility and costs. Respir Med 2014;108:13871395.

22 Bertella E, Banfi P, Paneroni M, et al: Early initiation of nighttime NIV in an outpatient setting. A randomized non inferiority study in ALS patients. Eur J Phys Rehabil Med 2017, Epub ahead of print.

23 Chatwin M, Nickol AH, Morrell MJ, et al: Randomised trial of inpatient versus outpatient initiation of home mechanical ventilation in patients with nocturnal hypoventilation. Respir Med 2008;102:1528-1535.

24 Luján M, Moreno A, Veigas C, et al: Non-invasive home mechanical ventilation: effectiveness and efficiency of an outpatient initiation protocol compared with the standard inhospital model. Respir Med 2007;101: 1177-1182.
25 Hazenberg A, Cobben N, Kampelmacher MJ Rischen J, Wijkstra PJ: Chronische beademing in Nederland. Ned Tijdschr Geneeskd 2011;155:A3609.

26 Storre JH, Steurer B, Kabitz HJ, et al: Transcutaneous $\mathrm{PCO}_{2}$ monitoring during initiation of noninvasive ventilation. Chest 2007;132 $1810-1816$

27 Windisch W, Freidel K, Schucher B, et al: The Severe Respiratory Insufficiency (SRI) Questionnaire: a specific measure of health-related quality of life in patients receiving home mechanical ventilation. J Clin Epidemiol 2003; 56:752-759.

28 Windisch W: Severe Respiratory Insufficiency Questionnaire. https://www.pneumologie. de/fileadmin/user_upload/SRI/SRI_English1a60.pdf (accessed July 25, 2017).

29 Storre JH, Magnet FS, Dreher M, et al: Transcutaneous monitoring as a replacement for arterial $\mathrm{PCO}_{2}$ monitoring during nocturnal non-invasive ventilation. Respir Med 2011; 105:143-150.

30 Schwarz SB, Windisch W, Magnet FS, et al: Continuous non-invasive $\mathrm{PCO}_{2}$ monitoring in weaning patients: transcutaneous is advantageous over end-tidal $\mathrm{PCO}_{2}$. Respirology 2017;22:1579-1584.

31 Windisch W; Quality of life in home mechanical ventilation study group: impact of home mechanical ventilation on health-related quality of life. Eur Respir J 2008;32:13281336. 